5. Muratov, M. (2005). Estrada as a phenomenon of mass culture: the author's abstract. Candidate's thesis. Kazan [in Russian].

6. Rubb, A. (2001). Phenomenon of variety directing: the experience of research. M.: Ray [in Russian].

7. Silanteva, I. (2008). The problem of reincarnation of the performer in the vocal and theatrical art: the author's abstract. Doktor's thesis. Moscow [in Russian].

8. Sokolskaya A. (2004). Opera text as a phenomenon of interpretation: Candidate's thesis. Kazan [in Russian].

9. Chugunov, U. (1997). Variety-jazz vocal // Jazz mosaic / ZAO RIFME. M. P. 72-78 [in Russian].

10. Sharoev, I. (1992). Directing the stage and mass performances. Textbook for students of theatrical higher educational institutions. Izd-e 2nd, revised. M.: Gitis [in Russian].

Стаття надійшла до редакції 15.03.2017

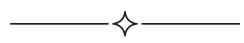

УДК 781.1:78.071.1

\author{
Анна Павловна Копейка \\ аспирантка кафедры истории музыки \\ и музыкальной этнографии \\ Одесской национальной музыкальной \\ академии имени А. В. Неждановой \\ anna.kopejka@gmail.com
}

\title{
ЧИСЛО КАК ФОРМООБРАЗУЮЩИЙ ПРИНЦИП МУЗЫКАЛЬНОЙ КОМПОЗИЦИИ
}

\begin{abstract}
Цель работы. Исследование посвящено некоторым аспектам взаимодействия музыки и математики, а именно - композиторским замыслам, основу которых составляют фундаментальные мировые константы (такие как число пи и число Эйлера) либо статистические данные, некоторым образом воплощенные авторами в звуковой ткани их произведений. Помимо диалога музыкантов с математикой в статье приводится пример обратного диалога (математические исследования Леонарда Эйлера в области музыки) и рассматривается возникающий в связи с этим вопрос о диссонансе в музыке. Методология состоит в использовании компаративного, аналитического, историко-логического методов. Научная новизна работы заключается в расширении бытующих представлений о сопутствующей роли математической составляющей в процессе композиторского творчества до уровня, когда она становит-
\end{abstract}

(C) Копейка А. П., 2017 
ся формообразующей первоосновой. Выводы. Объект математического мира, становясь отправной идейной точкой музыкальной композиции и внедряясь в структуру музыкальной ткани, трансформирует ее сообразно со своими потребностями. Трансплантируясь в звуковую сферу, этот объект порождает череду уже всецело музыкальных мыслей автора, однако его символическая первооснова продолжает напоминать о себе на протяжении всего музыкального развития.

Ключевые слова: число пи, число Эйлера, музыкальная композиция, музыкальное формообразование, семантика диссонанса.

Kopiika Hanna, graduate student of The Odessa National A. V. Nezhdanova Academy of Music, the department of the history of music and musical ethnography

\section{Number as a form-building principle of musical composition}

Objective. The research is devoted to some aspects of the interaction of music and mathematics, namely, compositional designs based on fundamental world constants (such as the Pi number and Euler number) or statistical data embodied in some way by the authors in the sound fabric of their works. In addition to the musicians' dialogue with mathematics, the article gives an example of a reverse dialogue (Leonard Euler's mathematical research in the field of music) and discusses the issue of dissonance in music. The methodology consists in the use of comparative, analytical, historical-logical methods. The scientific novelty of the work is to expand the prevailing notions of the concomitant role of the mathematical component in the process of composer creativity to the level when it becomes the formative primary principle. Conclusions. The object of the mathematical world, becoming the starting ideological point of musical composition and penetrating into the structure of a musical fabric, transforms it according to its needs. Transplanted into the sound sphere, this object generates a series of already completely musical thoughts of the author, however, his symbolic fundamental principle continues to remind of himself throughout the entire musical development.

Keywords: Pi number, Euler number, musical composition, musical form, dissonance semantics.

Копійка Ганна Павлівна, аспірантка кафедри історії музики та музичної етнографії Одеської національної музичної академії імені А. В. Нежданової

\section{Число як формоутворюючий принцип музичної композиції}

Мета роботи. Дослідження присвячене деяким аспектам взаємодії музики і математики, а саме - композиторським задумам, основу яких складають фундаментальні світові константи (такі як число пі і число Ейлера) або статистичні дані, певним чином втілені авторами в звуковій тканині їх творів. Крім діалогу музикантів з математикою в статті наводиться приклад зворотного діалогу (математичні дослідження Леонарда Ейлера у сфері музики) і розглядається питання, що виникає 
в зв'язку з иим, про дисонанс в музиці. Методологія полягає в використанні компаративного, аналітичного, історико-логічного методів. Науковою новизною роботи є розширення існуючих уявлень про супутню роль математичної складової в процесі композиторської творчості до рівня, коли вона стає формотвірною першоосновою. Висновки. Об'єкт математичного світу, стаючи відправною ідейною точкою музичної композиції і проникаючи в структуру музичної тканини, трансформує ї̈ відповідно до своїх потреб. Трансплантуючись до звукової сфери, цей об'єкт породжує низку вже цілком музичних думок автора, проте його символічна першооснова продовжуе нагадувати про себе протягом усього музичного розвитку.

Ключові слова: число пі, число Ейлера, музична композиція, музичне формоутворення, семантика дисонансу.

Актуальность. XX век привнес в музыкальное искусство множество инновационных идей и междисциплинарных взаимосвязей. Одним из ключевых при этом становится содружество между музыкой и математикой, породившее как проникновение в музыкальнокомпозиционный процесс математических принципов, так и целый ряд математических исследований в музыкально-теоретической области. Интерес с подобным диалогам продолжает существовать и по сегодняшний день, однако на несколько ином уровне.

Цель работы - изучить некоторые аспекты взаимодействия музыки и математики на современном этапе, показать, что математический объект может быть не только опосредованным участником музыкального процесса, но и главным формообразующим элементом композиции.

Научная новизна работы заключается в расширении бытующих представлений о сопутствующей роли математической составляющей в процессе композиторского творчества до уровня, когда она становится формообразующей первоосновой.

Основное содержание. Число - одно из основополагающих понятий в формировании мировоззренческих установок человечества. Издревле люди пытаются проникнуть в его абстрактную сущность, рассматривая его под различными дисциплинарными углами зрения. Так, математики основное внимание уделяют свойствам и принципам обустройства логико-числовых и понятийных конструкций, представители естественнонаучных областей активно применяют практические результаты их исследований, философы берут на себя поиски общих космологических законов и затрагивают в связи с понятием числа вопросы онтологического характера [2]. 
Вопрос о роли числа в музыке, несмотря на существующие многочисленные исследования в этом направлении, остается актуальным и по сегодняшний день. А. Ф. Лосев пишет: ММуыка возникает как искусство времени, в глубине которого (времени) таится идеально-неподвижная фигурность числа и которое снаружи зацветает качествами овеществленного движения» [3, 545].

В истории музыки есть много примеров синтеза музыки и математики, зримо или незримо в музыке присутствуют различные пропорции (обязательным параметром, например, является точка золотого сечения в композиционной архитектонике), некоторые композиторы сознательно используют числовые последовательности (например, ряд Фибоначчи и ряд Люка $\left.{ }^{1}[1]\right)$. Интерес к выявлению математических закономерностей в музыке, интуитивно или преднамеренно заложенных авторами в своих творениях, существует в музыковедении уже на протяжении продолжительного времени, трансформируется с развитием музыкально-теоретической мысли и постепенно нарастает по мере внедрения в нашу жизнь достижений научно-технического прогресса. XX век в этом отношении стал настоящей кладовой музыкальных идей, отголоски которых продолжают жить и в нынешнем XXI веке. Интересно наблюдать процесс их изменения, обрастания новыми смыслами и формами, возникающими из потребностей современной эпохи. Если в XX веке новыми в музыке стали различные композиционные техники (серийная, сериальная, пуантилизм, сонористика, алеаторика, электронная музыка и др.), в которых математика участвует в основном опосредованно (в структурном каркасе, алгоритмическом принципе строения композиции, техническом и акустическом факторе), то в XXI веке стала популярной идея прямого диалога с математикой.

В качестве примера такого диалога можно привести музыкальную композицию для виолончели, написанную студентом Университета Миннесоты Дэниелом Кроуфордом, получившую название «A Song of Our Warming Planet» (2013). Используя показатели среднегодовой температуры Земли, собранные Институтом Годдарда с 1880 по 2012 год, он построил соответствующий график данных и отразил их

${ }^{1}$ Так, форму одного из известных произведений С. Губайдулиной «В начале был ритм» для ансамбля ударных инструментов (1984) определяют числа Фибоначчи. Ряд Фибоначчи также используется в ритмической организации некоторых произведений Стравинского, Бартока, Штокхаузена. Ряд Люка представлен в сочинениях Дебюсси, Губайдулиной. 
в своей композиции посредством звуков (низкие ноты представляют относительно прохладные годы, в то время как высокие ноты тёплые). Температурные данные представлены в диапазоне трёх октав, начиная с самой «холодной» отметки за всю историю наблюдений (-0,47 ${ }^{\circ} \mathrm{C}$ в 1909 году), которая обозначена самой низкой нотой. Каждое повышение на полутон равняется приблизительно $0,03{ }^{\circ} \mathrm{C}$ общепланетарного потепления. Этим способом автор попытался довести понимание проблем климата до широкой аудитории. По мнению Кроуфорда, мелодия может объяснить это доходчивее, чем графики и цифры.

Не обошлось без внимания и знаменитое число пи ( $\pi \approx 3,141592653589793238462643 \ldots)$ Являясь иррациональным и, более того, трансцендентным, это число демонстрирует свою всеобъемлющую универсальность и не перестает удивлять человечество своей загадочной способностью неожиданно обнаруживаться в самых разнообразных разделах математики, проявляя взаимосвязь с весьма отдаленными от него понятиями.

Числу пи принадлежит особое место в искусстве, ему устанавливают памятники ${ }^{1}$, используют в пропорциях архитектурных сооружений ${ }^{2}$, посвящают рассказы ${ }^{3}$ и фильмы ${ }^{4}$. Эти факты говорят о том, что интерес к числу пи вышел далеко за пределы математических кругов.

Знаменитое число привлекло внимание и музыкантов. Воплощая в звуках последовательность цифр числа пи различными способами, они получали достаточно интересные результаты.

David Macdonald сыграл 122 знака после запятой числа $\pi$, поставив в соответствие каждой цифре определенную ступень ля минора и гармонизировав полученную мелодию в арпеджированной фактуре на фортепиано довольно традиционным и бесхитростным образом. Созданное им видео «Song from $\pi$ !» набрало почти 5 млн просмотров в Youtube и для многих (судя по комментариям) стало истинным откровением в мире музыки.

${ }^{1}$ В Сиэтле, на ступенях перед зданием музея искусств; в США, в Парке скульптур (Нью-Джерси); на южном побережье Крымского полуострова, близ города Кацивели.

${ }^{2}$ Германский король Фридрих II был настолько очарован магическим числом $\pi$, что посвятил ему целый дворец Кастель дель Монте, в пропорциях которого содержится это волшебное число.

${ }^{3}$ В 1996 г. Майк Кейт посвятил числу короткий рассказ «Ритмическая каденция». Длина слов в тексте соответствует первым 3834 цифрам числа $\pi$.

${ }^{4}$ В 1998 г. режиссер Даррен Арновски снял психологический триллер «Рі»; в 2012 г. на экраны вышел драматический фильм «Life of Pi» («Жизнь Пи») режиссера Энга Ли. 
Еще один пример - «The Melody of Рi». Его автор, Jim Zamerski, использовал запись числа $\pi$ в 12-ричной системе исчисления и каждой цифре поставил в соответствие звук 12-ступенной хроматической гаммы от «до» (дополнив ее «нулем» - звуком си, который предшествует начальному единичному тону). Его вариант задействует 226 знаков записи числа $\pi$. При этом само число опять-таки становится мелодическим каркасом, на который накладывается гармония, изложенная на сей раз вальсообразной фактурой на фортепиано (лишь в кульминации подключаются другие электронные тембры, поддерживающие мелодический и гармонический пласты композиции). За счет использования 12-ступенной основы эта композиция более интересна с гармонической стороны и по драматургии.

Третий пример - вновь обращение к диатонике, однако на сей раз от звука «до» (который соответствует цифре 1), по порядку, с включением «до» и «ре» второй октавы (8 и 9). В своей композиции «What Pi sounds like» еe автор, Michael John Blake, помимо соответствия цифрам отдельных звуков, использует и соответствие им трезвучий (построенных от соответствующих ступеней в до мажоре). Данная композиция задействует всего лишь 32 знака числа $\pi$, однако музыкально является самой интересной из рассмотренных за счет тембрового разнообразия и драматургического крещендирования с постепенным подключением инструментов. Исходная тема, отзвучав одноголосно, закрепляется в качестве остинатного фона и расцвечивается различными колокольного рода полифоническими сочетаниями с собой же, доходя к окончанию до кульминационного апофеоза. Путем последовательного объединения инструментальных тембров, различных, но подчиненных решению одной числовой задачи, создается эффект «мировой гармонии» как отражения универсальной сущности числа $\pi$.

Кроме общеизвестного числа пи, есть в математике не менее фундаментальное и вездесущее число, пронизывающее все разделы математики (которое в школьном курсе немного упоминают в связи с понятием натурального логарифма и функцией экспоненты) - число Эйлера (e $\approx 2,71828182845904523$...). Как и число п, оно является иррациональным и трансцендентным.

Леонард Эйлер (1707-1783), с именем которого связано число «е», личность легендарная в математике. Швейцарский, немецкий и российский математик и механик, внесший фундаментальный вклад в развитие этих наук (а также физики, астрономии и ряда 
прикладных наук), автор более чем 850 работ (включая два десятка фундаментальных монографий) по математическому анализу, дифференциальной геометрии, теории чисел, приближенным вычислениям, небесной механике, математической физике, оптике, баллистике, кораблестроению, теории музыки и другим областям. Он глубоко изучал медицину, химию, ботанику, воздухоплавание, теорию музыки, множество европейских и древних языков. Академик Петербургской, Берлинской, Туринской, Лиссабонской и Базельской академий наук, иностранный член Парижской академии наук.

Хорошо известный в естественно-математических кругах, он редко упоминается в музыкальной литературе, несмотря на свой весьма значительный вклад в сферу музыкальной теории. (Злые языки поговаривали, что в его трудах о музыке «слишком много музыки для математиков и слишком много математики для музыкантов».) Музыкальной гармонией Эйлер интересовался на протяжении всей своей жизни, стремясь дать ей ясное математическое обоснование.

Целью раннего его труда - «Опыт новой теории музыки» (Tentamen novae theoriae musicae, 1739) - была попытка математически описать, чем приятная (благозвучная) музыка отличается от неприятной (неблагозвучной) [4].

Взяв за основу обертоновый звукоряд, он связывает степень благозвучности со степенью простоты рациональных отношений частот звуков (то есть их «обертонных номеров» в звукоряде). Эйлер вводит величину, характеризующую степень приятности - GS (gradus suavitatis).

Он принимает $\mathrm{GS}(1)=1, \mathrm{GS}(\mathrm{p})=\mathrm{p}$ (для простых чисел). Затем он выводит математический эквивалент тому, что интервалы сохраняют степень своей благозвучности вне зависимости от высоты своего начального тона:

$$
\begin{gathered}
\mathrm{GS}(\mathrm{mn})-\mathrm{GS}(\mathrm{n})=\mathrm{GS}(\mathrm{m})-\mathrm{GS}(1), \text { т. е. } \\
\mathrm{GS}(\mathrm{mn})=\mathrm{GS}(\mathrm{m})+\mathrm{GS}(\mathrm{n})-1 .
\end{gathered}
$$

Следствием этого являются соотношения:

$$
\begin{aligned}
& \mathrm{GS}(2 \mathrm{n})=\mathrm{GS}(\mathrm{n})+\mathrm{GS}(2)-1=\mathrm{GS}(\mathrm{n})+1, \\
& \mathrm{GS}\left(\mathrm{p}_{1} \mathrm{p}_{2} \ldots \mathrm{p}_{\mathrm{k}}\right)=\mathrm{p}_{1}+\mathrm{p}_{2}+\ldots+\mathrm{p}_{\mathrm{k}}-(\mathrm{k}-1) .
\end{aligned}
$$

Теперь можно легко вычислить «степени приятности» любого интервала. Берем отношение частот звуков m:n (получающаяся дробь должна быть несократимой, иначе - привести ее к такому виду), 
раскладываем произведение mn на простые множители $\mathrm{p}_{1} \mathrm{p}_{2} \ldots \mathrm{p}_{\mathrm{k}}$ и вычисляем

$$
\mathrm{GS}(\mathrm{m}: \mathrm{n})=\mathrm{GS}(\mathrm{mn})=\mathrm{GS}\left(\mathrm{p}_{1} \mathrm{p}_{2} \ldots \mathrm{p}_{\mathrm{k}}\right) \text { по формуле (3). }
$$

Например, для малой децимы (5:12) получим:

$$
\mathrm{GS}(5: 12)=\mathrm{GS}(5 * 12)=\mathrm{GS}(2 * 2 * 3 * 5)=2+2+3+5-3=9 .
$$

Для сравнения, малая терция (5:6) дает:

$$
\mathrm{GS}(5: 6)=\mathrm{GS}(5 * 6)=\mathrm{GS}(2 * 3 * 5)=2+3+5-2=8 \text {. }
$$

То есть терция звучит менее резко, чем децима.

Аналогично можно заметить, что октава (1:2) (для которой $\mathrm{GS}(1: 2)=2)$ более благозвучна, чем интервал в две октавы

$$
(\mathrm{GS}(1: 4)=\mathrm{GS}(4)=\mathrm{GS}(2)+1=3) .
$$

Интересно, что дуодецима (1:3) и интервал в две октавы (1:4) оказываются одинаково «приятными»: $\mathrm{GS}(3)=3$,

$$
\mathrm{GS}(4)=\mathrm{GS}(2)+1=2+1=3 \text {. }
$$

Также одинаковую степень благозвучности имеют малая секста (5:8) и большая секунда (8:9) (имеются в виду натуральные интервалы). Действительно,

$$
\begin{gathered}
\mathrm{GS}(5: 8)=\mathrm{GS}(5 * 8)=\mathrm{GS}(2 * 2 * 2 * 5)=2+2+2+5-3=8, \\
\mathrm{GS}(8: 9)=\mathrm{GS}(8 * 9)=\mathrm{GS}(2 * 2 * 2 * 3 * 3)=2+2+2+3+3-4=8 .
\end{gathered}
$$

Этот подход в целом согласуется с нашими слуховыми ощущениями.

В конце главы VII «Опыта» Эйлер расположил интервалы по «степеням приятности» (gradus suavitatis), при этом октава была причислена ко II (наиболее приятному) классу, а диасхизма - к последнему, XXVII классу (самый неблагозвучный интервал).

На склоне лет, в 1773 году Эйлер прочитал доклад в СанктПетербургской академии наук, в котором в окончательном виде сформулировал свое решетчатое представление звуковой системы, метафорически обозначенное автором как «зерцало музыки» (лат. speculum musicae). Доклад Эйлера был опубликован в виде небольшого трактата De harmoniae veris principiis per speculum musicum repraesentatis («Об истинных основаниях гармонии, представленных через speculum musicae»). Под названием «звуковой сети» (нем. Tonnetz) эйлерова 
решетка получила широкое хождение в немецкой музыкальной теории XIX века.

К сожалению, число Эйлера в музыкальных кругах практически неизвестно и до недавнего момента не вдохновляло композиторов на творческие поиски. Автору данной статьи довелось эту «несправедливость» устранить в произведении для флейты, гобоя/английского рожка, скрипки, виолончели и фортепиано «Гармония числа Эйлера» ${ }^{1}(2016)$.

В основе произведения оказалась тема, каждый звук которой соответствует цифре числа Эйлера $(1-$ до, $2-$ pe, $3-$ ми, ..., 8 - снова до, 9 - ре, 0 - пауза).

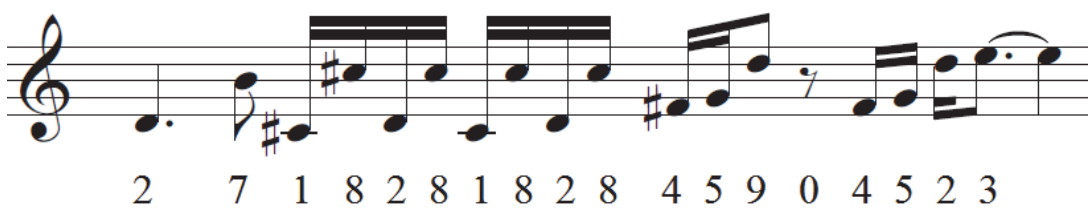

Однако в исходный вариант темы (олицетворяющей собой красоту и гармоничность мироздания), вкралась некоторая «погрешность», «дефект» («до-диез» и «фа-диез» вместо «до» и «фа»), та «пифагорова кома», которая стремится разрушить хрупкое равновесие мира. Этот «изъян» становится «червем», подтачивающим мир изнутри, и приводит к катастрофе. Мир рушится, остаются лишь обломки всего былого. Но вскоре из этих обломков начинает формироваться нечто, постепенно обретающее очертания, - и тема возрождается. Равновесие восстанавливается, мироздание вновь обретает красоту и гармоничность, однако эта гармония уже иная («в одну и ту же реку нельзя войти дважды»). Казалось бы, можно вздохнуть с облегчением - но нет, «изъян» никуда не исчез...

Произведение имеет трехчастную структуру. В первой части после небольшого вступления (в котором сразу наряду с гармонией присутствует и «изъян») появляется главное действующее лицо - тема числа Эйлера у скрипки. Затем варианты темы звучат по очереди у флейты, виолончели и английского рожка, стремительно набирая обороты и приводя к кульминационному ее проведению у скрипки на фоне остинатной пульсации фортепиано и взлетающих реплик остальных инструментов.

\footnotetext{
${ }^{1}$ «Harmony of Euler's Number».
} 
После «колокольно»-разрушительного эпизода наступает второй раздел, построенный на обломках темы и напоминающем о себе «дефекте». В этом разделе большую роль приобретает перкуссионная составляющая музыкальной ткани, создающаяся как инструментальными средствами (использование дождевого посоха, постукивание клапанами флейты, тремолирование за подставкой и глиссандирующие реплики струнных инструментов, различные звуки фортепиано - встречное двойное поверхностное глиссандирование карандашами по клавишам фортепиано, звук падения карандаша на струны рояля в разных регистрах и др.), так и с помощью фонического вербального эффекта (звук «Рf» с четкой акцентированной атакой и плавным затуханием до полного исчезновения, который символизирует собой «дыхание мира»). Последний эффект зарождается и активно себя проявляет в первом разделе, затем на некоторое время исчезает в эпизоде «руин», возвращаясь вновь лишь к окончанию этого раздела и знаменуя собой восстановление нарушенного гармонического равновесия, возрождающийся из руин мир. Тема, рассыпавшаяся в этом разделе на множество живущих каждый своей жизнью мотивов, постепенно приобретает все большую цельность и четкость очертаний, и в начале третьего раздела собирается воедино.

Первое проведение «восстановившейся темы» в начале третьего раздела задействует практически весь исполнительский состав. Отдельные реплики темы последовательно проходят у различных инструментов, замирая на последнем звуке своего фрагмента и передавая «эстафету» следующему ее участнику, собираясь постепенно в единый аккорд-кластер. Однако этот кластер выполняет не разрушающую, а созидающую функцию. Он «разрастается» в череду благозвучных аккордов, которые идут отдельной линией параллельно с темой и резкими диссонирующими созвучиями у фортепиано. Следующий за этим полифонический эпизод, разрастающийся по мере подключения инструментов и постепенно захватывающий все больший диапазон, приводит к светлой «колокольной» кульминации, которая сменяется кодой, погружающей слушателя в дымку неопределенности... Что будет дальше - кто знает?...

В процессе дискуссии о концепции произведения возник вопрос: что есть диссонанс? Действительно ли интервал увеличенной октавы («фа-бекар» - «фа-диез»), составляющий основу конфликта между гармонией и хаосом этого произведения, является «абсолютным» диссонансом? В истории музыки ответ на вопрос о консонансах и 
диссонансах постоянно претерпевает переосмысление («диссонанс сегодня - консонанс завтра»). Представляется, что окончательный вердикт о консонансности либо диссонансности отдельного созвучия может быть вынесен исключительно в данном конкретном контексте. В контексте же рассмотренного произведения, содержащего стилистический диалог двух принципиально различных эпох (романтизма и модерна), интервал увеличенной октавы, прорывающийся из гармонического окружения, безусловно, воспринимается как диссонанс, символ чего-то чуждого этому миру, предвестник хаоса; тогда как в эпизоде «руин мира» этот же интервал уже не воспринимается как диссонанс, живет в своей среде и чувствует себя «как дома».

Вопрос о том, что такое диссонанс и какие созвучия наиболее приятны для слуха, интересовал и Эйлера, косвенно участвующего в данной дискуссии. Согласно его теории, интервал увеличенной октавы в натуральном звукоряде возникает между 7-м и 15-м частичными тонами. Для них

$$
\mathrm{GS}(7: 15)=\mathrm{GS}(3 * 5 * 7)=3+5+7-2=13 .
$$

Это довольно большое число. Для сравнения, большая септима дает меньшее значение:

$$
\operatorname{GS}(8: 15)=\mathrm{GS}(2 * 2 * 2 * 3 * 5)=2+2+2+3+5-4=10 .
$$

Следовательно, все-таки увеличенная октава - диссонанс, и без диссонанса мир, к сожалению, не обойдется; с ним приходится сосуществовать, следовательно, приходится музыкально мыслить, учитывать его присутствие. Вопрос в том, что в итоге перевесит консонансное равновесие или диссонансное напряжение...

Выводы. Рассмотренные музыкальные явления являются новаторскими как в композиционном, так и в музыковедческом отношении, выявляют один из интересных аспектов «сотрудничества» математики и музыки, когда объект математического мира становится отправной идейной точкой музыкальной композиции, внедряясь в структуру музыкальной ткани и трансформируя ее сообразно со своими потребностями. Трансплантируясь в звуковую сферу, этот объект порождает череду уже всецело музыкальных мыслей автора, развивается далее по музыкальным законам, однако его символическая первооснова продолжает напоминать о себе на протяжении всего музыкального развития. Взаимодействие привнесенного извне семантического пласта и совокупности априорных внутренних 
музыкальных смыслов порождает эффект расширения музыкального ассоциативно-понятийного комплекса, открытия новых языковых возможностей музыки.

\section{СПИСОК ЛИТЕРАТУРЫ}

1. Бахтизина Д. И. Музыка и математика: параметры сопряжения. Гуманитарные, социально-экономические и общественные науки. Краснодар, 2013. Вып. 4. URL: http://www.online-science.ru/m/products/ philosophy_sciense/ gid531/pg0/ (дата обращения: 02.11.2017).

2. Гутнер Г. Б. Число. Новая философская энциклопедия / ред. В. С. Стёпина. М.: Мысль, 2001. Т. 4.

3. Лосев А. Ф. Музыка как предмет логики. Форма. Стиль. Выражение / сост. А. А. Тахо-Годи. М.: Мысль, 1995. С. 405-602.

4. Bailhache P. Euler and music. Problems of translation in the 18th century. Nantes, 1997. URL: http://www.tonalsoft.com/monzo/ euler/euler-en.aspx (last accessed: 02.11.2017)

\section{REFERENCES}

1. Bakhtizina, D. I. (2013). Music and mathematics: conjugation parameters. Humanitarian, socio-economic and social sciences, 4. Krasnodar. Retrieved from http://www.online-science.ru/m/products/philosophy_sciense/gid531/ pg0/ [in Russian].

2. Gutner, G. B. (2001). Number. New philosophical encyclopedia. V. S. Styopin (Ed.). (Vols. 4). Moscow: Mysl' [in Russian].

3. Losev, A. F. (1995). Music as a subject of logic. The form. Style. Expression. A. A. Tahoe-Godi (Ed.). (pp. 405-602). Moscow: Mysl' [in Russian].

4. Bailhache, P. (1997). Euler and music. Problems of translation in the 18th century. Nantes. Retrieved from [in English].

Стаття надійцла до редакції 22.03.2017 